\title{
Relational interdependence as a means to examine work, learning and the remaking of work as cultural practices
}

\author{
STEPHEN BILLETT, MICHELLE BARKER AND RAY SMITH
}

\begin{abstract}
THIS CHAPTER FOCUSES ON DUALITIES in both the process and outcomes of participation in work. The process of participation in work activities and interactions is held to draw on the contributions of both individuals and the social world in ways that are interdependent, yet relational. The affordances of workplaces shape the array of experiences able to be accessed by individuals and they, in turn, elect how they engage, construe and construct what the workplace affords. Both the social and individual contributions are exercisable with different degrees of intensity, focus and intentionality, making the process of participation a relational one. Consistent with these processes, the outcomes of workplace participation also comprise dualities. These are individual learning or change, on the one hand, and the remaking or transformation of cultural practice that comprises work, on the other. In illuminating and elaborating these concepts, this paper draws upon the initial findings of a research project that is mapping the working lives of groups of three workers in each of four workplaces. The aim is to understand how these relational interdependences shape the participation, learning and remaking of work practices in these workplaces and their workers and to identify the exercise of both affordances and engagement for each participant within the same workplace, and then to make comparisons across the four workplaces. The findings emphasise the distinctive bases by which individuals engage with work and construct meaning and practice as a result of that engagement and, in turn, their remaking of the work practices.
\end{abstract}

\subsection{Working and learning: Interdependence between social suggestion and individual agency}

Understanding further the learning potential of the workplace is important for both practical and conceptual purposes. Practically, at a time when the requirements for work are in constant change and turmoil, there is a need to understand how individuals can best learn these changing requirements through work and throughout their working life. It seems that the most likely and accessible environment to assist this learning will be workplaces themselves. Evidence suggests that workplaces can be highly generative of much of the knowledge required for work performance (Eraut, 2004; Fuller \& Unwin, 2002; Rogoff \& Gauvain, 1984; Scribner, 1984, 1985a). However, they also have significant limitations in terms of the distribution of opportunities for learning, the prospects of securing effective learning experiences and the issue of recognition of that learning (Bierema, 2001; Eraut, 2004; Fuller \& Unwin, 2003; Solomon, 1999). The key premises that appear to 
underpin both learning through engagement in everyday work activities and interactions and through intentional learning strategies are those associated with the degree of affordances (e.g. support, opportunities, interactions, guidance) provided by the workplace, and also the degree and bases by which individuals engage in the workplace (Billett, 2004). That is, how both individuals and workplaces exercise their intentions, agency and effort in participating in and learning through work, and how these contributions are negotiated, and then construed and constructed by individuals. A related practical concern is that individuals' learning is not an isolated process without consequences for the workplace and work practice. As individuals engage in interactions and activities, they are actively remaking the work practices and activities. So not only is there a legacy in terms of ontogenetic development individuals' development across the lifespan - but also in terms of situated practice, which, in turn, shapes the cultural practices (Leontyev, 1981), including those comprising work (Billett, 2005b; Rogoff, 1990).

There are also important conceptual issues being worked through here. There is currently considerable interest in the relationship between the social and the individual within the major disciplines of psychology (Rogoff, 1995; Scribner, 1997/1990; Valsiner, 1994), philosophy (Archer, 2000; Bhaskar, 1998) and sociology (Fenwick, 1998; Giddens, 1991). Although different in emphasis, much of the deliberations in these disciplines are focused on the prominence of one or other of the contributions (e.g. social structures or individual agency). That is, do individuals bring about change or is that change dependent upon social forms and structures? Workplaces provide a useful test bench to illuminate and discuss these issues, because they represent environments in which the social structures are enacted, and knowledge that has historical and cultural geneses is enacted and engaged by individuals with their own unique social histories. Yet, in workplaces there is a necessary interdependence between the social and the individual, because each is dependent upon the other for their continuity and development (Billett, 2005b). This interdependence is proposed here as being found in the relationship between the social suggestion manifested in the workplace, in terms of norms, practices and concepts: institutional facts (Searle, 1995) with their intentionalities, on the one hand, and individuals' intentionality and agency, as shaped through their ontogenetic development or life history on the other.

Work is a key element of adult life and, for many, it is the means through which their identity is shaped and exercised (Noon \& Blyton, 1997; Pusey, 2003). So more than engaging in work being the completion of tasks and interactions, there are important outcomes for individuals that arise from engaging in these activities. One way to understand the importance of, and links between, self and work is to propose that the process of engagement in activities is central to ongoing and moment-bymoment individual learning or microgenetic development (Rogoff, 1990). Therefore, the engagement in work of any kind leads to particular and possibly significant legacies in terms of individuals' development that is generative of close links between individuals' sense of self and their work. That is, work and learning are so intertwined as to inevitably link individuals' knowing and learning to their work activities (Fenwick, 2002; Somerville, 2002). Further, the workplace provides an environment that is rich in its contributions to individuals' learning. The degree to which it provides the interpsychological experiences of activities and interactions through which knowledge is experienced, accessed, engaged with and constructed represents the affordances or invitational qualities that are fundamental to what 
constitutes a learning environment. Central to this process of learning and what constitutes a learning environment is also the degree to which individuals act agentically (i.e. with personal agency in the direction and intensity of their actions) in the process of constructing knowledge (Billett, 2005b; Billett \& Somerville, 2004). This epistemological agency (Smith, 2004) comprises individuals' construal of what they experience (e.g. what constitutes welcome or unwelcome affordances), the degree of, and intentionality in, their engagement in those affordances (e.g. activities and interactions) and their construction of meaning, procedures and values. This process is shaped by and premised upon individual's identity and agency.

So individuals' learning arises through engagement in everyday conscious thought through what constitutes personal epistemology (Bauer, Festner, Gruber, Harteis \& Heid, 2004; Smith, 2004), notwithstanding that epistemology is itself being shaped through a history of relations with the social world (Scribner, 1985b). Consequently, continuities and transformations in work and individuals' learning are a product of how individuals construe, engage in and construct the activities and interactions that constitute the gift of the social (Archer, 2000; Cole, 1998; Scribner, 1985b): the norms, values and practices that are generated in, and made accessible through, the social world. Given that individual agency and intentionality are associated with and, in turn, shape identities and subjectivities or sense of self, they are central to the relational interdependence between the social and individual contributions to thinking and acting, and therefore learning (e.g. Valsiner \& Van der Veer, 2000).

\subsection{Relational interdependence at work}

Much of what needs to be learnt for vocational practice has its origins in cultural practices and historical precedents (Scribner, 1985b), referred to here as the gift of the social. Consequently, to access this knowledge requires engaging with the social world, because this knowledge does not arise from within the individual. When individuals engage with this knowledge and reconstruct it, in addition to their individual development, they are also remaking these cultural practices at a particular point in time and under particular access to the social suggestion. This remaking of cultural practice and individual learning is not through some faithful enactment of social suggestion that results in its reproduction. Instead, the exercise of personal agency is essential in transforming cultural practices as new cultural needs arise, such as those brought about by changing times or technologies. Wertsch (1998) distinguishes between compliant learning (i.e. mastery), which is superficial and may well be the product of forceful or compelling social suggestion, and learning in which individuals engage willingly (i.e. appropriation) in a concurrence between what is experienced and individuals' values and beliefs. Given that richer or deeper kinds of learning likely require effortful engagement, buoyed by individuals' interests and intentionality (Malle, Moses, \& Baldwin, 2001), this may most likely arise when these forms of personal agency are being exercised. Thus a first key premise is of an inevitable interdependency between the agency of the social world in projecting its suggestion and the agency of individuals in making sense of what is suggested to or afforded them.

Secondly, there is likely to be person-dependence in individuals' engagement with and construction of the sources from which they learn. Individuals' construal of 
what they encounter is uniquely socially shaped through a lifetime of negotiations with the social suggestion. These are encountered in the myriad forms of social practices that individuals engage in throughout their lives, which microgenetically (Rogoff, 1990; Scribner, 1985b) contribute moment by moment to their processes of thinking and acting ontogenetically throughout their life history. However, individuals' ontogenetic development arises through a personally agentic epistemological process that is shaped through ongoing interactions with the social world that, in turn, subsequently influences how individuals engage with new experiences. Because these experiences are likely to be in some ways unique to individuals, they are highly generative of new constructions in ways that Vygotskians described as interpsychological, and leads to intrapsychological attributes. In this way, there will inevitably be personally distinct conceptions (as well as areas of shared understandings) in their process of knowledge construction and remaking of cultural practices.

So thirdly, because of the ontogenetic legacy and personal epistemology, consideration needs to be given to individuals' pre-mediate experiences - those that come earlier. It is these that are held to shape their conceptions and subjectivities and, consequently, how they construe subsequent experiences. Because these premediate experiences are themselves shaped by, yet contribute to, unique patterns of personal epistemology, life histories comprising individuals' prior social experiences stand as an important premise to how they engage with the world, including their sense of self.

Finally, the relationship between individual and social agency is not mutual or reciprocal: it is relational. Just as the social suggestion can be either weaker or stronger, so too can individuals' engagement with a particular social suggestion (e.g. situated practice, cultural norm). The prospects for contributions of the individual and social being enacted in equal parts or in ways that are equally shared are quite remote. The very interactive processes arising will be individually unique in some ways. This relational interdependence is continually being negotiated as both social and individual intentions and their relations are transformed. Rose's (1990) concept of the 'enterprising self', the individual entrepreneur whose focus and direction is towards self-regulation and individualisation aimed at securing the employers' economic goals and therefore securing their relations as an employee, provides an instance of this kind of ongoing agentic negotiation. Yet individually constructed sets of intentions may also be characterised by resistance to, or the clever manipulation of, the regulatory practices of the workplace, as much as either unquestioning compliance to them or their expedient reproduction. That is, the exercise of agency may not always be directed towards securing further social subjugation or faithfully reproducing existing subjectivities. Instead, it may focus sharply on securing more personal goals.

\subsection{Procedures}

In order to understand more clearly the relations that underpin the interdependencies at work and their consequences, we decided to investigate the working lives of groups of three workers in each of four different kinds of occupations and workplaces. The reason for selecting three workers was to gain insights into differences in the ways that the affordances or invitational qualities were exercised 
towards workers in the same workplace, how these workers then construed and constructed what was afforded them, and how they engaged in their work and learned as a result of these processes. A further goal was to draw comparisons or contrasts across four different kinds of work and workplaces with different kinds of participatory practices and workers with different employment standing and status. The four workplaces were: (i) a gymnasium, (ii) a restaurant, (iii) an information technology (IT) help area within a university and (iv) a fire station. Three individuals in each of these four workplaces agreed to participate. In the gymnasium, they comprised a receptionist, a trainer and a manager. In the restaurant, they comprised a chef, who was also a part owner, a waitress and a manager. In the IT help area, they comprised three desktop consultants, one of whom was a manager. In the fire station, the participants comprised a station manager and two fire officers, one of whom was a specialist officer.

The procedures adopted comprised a series of interviews that proceeded over an 18-month period. The data gathering commenced with two lengthy semi-structured interviews, the first primarily focusing on the workplaces, their requirements for continuity and the norms and practices. The second interview primarily focused on the workers' history and personal preferences. These lengthy interviews were initial attempts to understand the affordances of the workplace and its practices: their institutional facts (Searle, 1995) and also the bases for workers' participation in their work and learning for work. Beyond these two initial interviews there were progress interviews occurring over a 12-month period. These progress interviews were used to map development over time as well as to provide the opportunity for the participants to comment on the initial analyses from earlier interview data. In this chapter, the focus is on the first two interviews for each of the 12 participants. Accordingly, the findings are organised under sections that focus on the dualities of the process of workplace affordances and engagement, and then outcomes in terms of individual development and the remaking of the work practices.

\subsection{Workplace affordances and engagement}

\subsubsection{The fire service}

The four workplaces provide quite different bases of participatory practices. That is, their bases of affordances and engagement are quite distinct. The fire service offers secure employment. It comprises long shifts, during which the fire officers live in (i.e. eat and sleep) at the fire station. Their work can include exciting and demanding tasks that carry high public praise and afford a public status that the fire officers reported as being important to their identity. There are other less exciting tasks. These include officers going out in the community or training to improve performance during emergency incidents. So as part of their engagement in emergency duties, there are ample opportunities for developing further their skills through practice and also engagement in courses whose successful completion is a prerequisite for promotion. Living and working together in shift rosters also affords these officers opportunity to develop capacities to work effectively in teams, particularly in emergency situations. Team culture is importantly grounded in responsiveness to the command and control authority that prioritises member safety, care and responsibility in emergency situations. There was evidence of a high level 
of intersubjectivity or shared understanding among the informants about their work and its conduct, which appeared to arise from the extensive and close working relationships among the shift. Moreover, many of the fire officers had second jobs that they pursued in the extended periods of non-duty time on a shift roster. In this way, they were afforded options that were not widely afforded to other workers. Working for a large organisation that has emergency services as its sole function affords opportunities for specific promotion and advancement, and options for less physically demanding work later in the fire officers' working life. Furthermore, among the workers interviewed, one fire officer was permitted to work from home, as he cared for his sick wife. However, such a large public sector organisation also, it was claimed, allowed some officers to abrogate their responsibilities to their coworkers. Sometimes, it was claimed, this was because these officers were too focused on their second job. Yet while the workplace afforded this circumstance and could do little to correct it, the work practices also permitted individuals to be labelled as lazy or incompetent. Such labels, once attached to individuals, were reported very difficult to remove. Significantly perhaps, none of the interviewees expressed significant concerns about their working lives or indicated any intention to seek employment outside the fire service. Quite the reverse: employment in the fire service was seen as a strong foundation on which to build a financially secure and personally rewarding future. Their goals for engagement in work were generally about improving their performance or prospects for promotion, yet in ways that permitted them to remain active firefighters. In all, there seemed to be considerable consonance between these individuals' working life goals and what was afforded by the workplace. However these affordances are only available after a long recruitment process, which until recently did not discriminate between raw recruits and those with firefighting experience.

\subsubsection{University IT helpdesk}

The IT helpdesk also represents a working situation that has many of the work-life qualities of working in a large organisation and as a member of a team. The IT support staff rotate through tasks associated with responding to requests for technical assistance from university employees and students. They also have individual project work and specialist tasks. They were all physically located in a rather cramped working space, except when they were in the call centre room. Like the fire officers, there was also a reliance on each other, because problems arising often have solutions that others may know about or need to know about. There were opportunities for training and development available to these workers, as were opportunities for promotion. Yet, like the firefighters, there were concerns about being promoted outside active IT work. On the surface, there seemed to be a significant level of camaraderie among the workers in their shared space, often manifesting itself in workplace banter. There were also social events that occurred outside work-time, in which staff members participated. In contrast to the fire officers, the unifying bases for their work derived less from personally shared practices and values, and more from a standard operating environment (SOE), under which the university's computing functions operate. The SOE acts to homogenise the tasks of client problem-solving to a narrow range of applying systemised acceptable solutions. These solutions are prepared and shared through the rotation of so-called mundane duties associated with client PC support. There are also 
electronic monitoring devices that capture elements of these workers' performance in a public and (perhaps too) quantifiable way. However, unlike the three fire officers, the sense was that shared understanding, beyond the mechanics of the SOE, was less robust and was not grounded in individuals' values and beliefs. Their sense of engagement differed. One, the senior worker, reported being fully engaged in the workplace environment and out-of-work social events. Although the subject of significant workplace affordances (i.e. employment support, training, patronage), another worker was actively seeking employment in a different work area within the university and reported avoiding unnecessary social interactions. The third, while engaging in his work effortfully, reported being disengaged from the working group and disillusioned by the affordances of the workplace and their inequitable distribution. Certainly, in different ways, the electronically generated information about work performance was seen as being a negative affordance that led to inevitable comparisons and criticisms of colleagues. It was suggested that the workplace supported individuals who were poor performers and the promotional opportunities favoured those who were self-promoters. Gaining employment as a desktop help person appeared to arise from quite diverse experience and employment practices. One worker, who had previous experience in information technology support, was offered casual work that was converted to a full-time position. One, with an electronics training background, had had a long career in the university within the evolving information technology area. The third had previously been a builder, whose engagement with the university was funded by a government programme to retrain him as an information technology technician. So both the workers' backgrounds and means of providing current work were far from uniform.

\subsubsection{The restaurant}

The restaurant informants comprised three individuals, two of whom were part owners (in different proportions) and the third, a part-time waitress. Whereas there were relatively uniform bases for affordances for the fire officers and IT workers, in the restaurant there were clearly distinct affordances for the three participants' engagement in their work. Two were enacting their desires to be managers of catering businesses. The workplace afforded them the opportunity to exercise their vocation. The third participant was a part-time waitress whose employment was focused on supporting herself through university. The exacting requirements and high standard of work and engagement with customers, which were key workplace goals, provided quite different affordances for these three participants. For John, one of the part owners, it represented the kind of work that he was well suited to and personally and professionally enjoyed. For the other part owner, Robert, this experience was useful for developing further workplace capacities that would later be deployed in other personal aspirations. However, while conscientious and hard working, the exacting demands and level of commitment were seen as less invitational by the waitress. Her vocation resided elsewhere. Engagement in this workplace was also premised quite differently. For one, the original part owner, it had been about establishing and controlling a business. For the other part owner, engagement and participation was a product of buying a share of the restaurant. For the waitress, it was trading time for remuneration to sustain activities outside the workplace that were closer to her sense of self. 


\subsubsection{The Gymnasium}

The gymnasium offered some of the benefits of working in a large organisation, because it was one of a chain of gymnasiums, yet also had a more familial basis for participation. This extended to part-time workers. For instance, the part-time receptionist, although under 20, had a long association with the gym as a client and a part-time worker. Moreover, she had a personal relationship with the manager. As part of her employment conditions, this part-time worker was afforded full gym membership. In addition, because she was studying physiotherapy at university, there was a degree of consonance between her studies and ultimate career objective and her part-time work in the gymnasium. She was also afforded the opportunity to increase her hours of employment if desired and was promised security of employment throughout her years of study. In this way, the workplace affordances did much to support her needs and goals. The manager also had a long association with the gymnasium and had retained her position as manager when its ownership was transferred to a chain of gymnasiums. Her career goals and vocational interests were sustained by this takeover, as it offered her the prospect of promotion to a more senior position within the gym chain. Part of her work was to come in contact with the regional manager and owner, which provided her with opportunities to learn more about administration and management. The third participant at the gymnasium acknowledged a different kind of affordance and its change over time. He was both a self-employed personal trainer, conducting one-on-one sessions with his clients, and a gym employee trainer, assisting members with their training programmes. He was also a part-time student. For his personal clients he was afforded access to the gym and its facilities on the basis of rental payment. Yet there was significant reciprocity in the relationship. That is, the better service he provided the greater retention of membership within the gym. This retention and expansion of membership was the key basis for the gym's survival and development. Consequently, the gym provided him with potential clients in the form of members, and the quality of his work with those members contributed to them maintaining gym membership and their seeking his services privately. He had established a level of clients he wished to secure and develop as the foundation for his personal training business. This arrangement would remain in place until such time as his personal client base was sufficiently large to warrant ceasing to work as an employee. This would most likely be achieved through a positive relationship with the gym. Moreover, the takeover of the gym had also led to him being requested and supported to upgrade his qualifications, which again linked him closely to the gymnasium.

\subsection{Analysing interdependencies}

It can be seen that there are quite different premises that shape these workplace affordances and their construal by individuals. That is, the institutional facts (Searle 1995) played out in quite different ways. These differences were identifiable in individuals' intentionalities and interests, thereby underlining the significance of the individual in this process. The fire service offers a form of work that is seen as being exciting, high profile and currently enjoying unprecedented standing in the community. One fire officer (i.e. Hugh) referred to the elevation of his standing 
within the community upon becoming a fire officer. This included being invited to engage in conversation by those who had previously ignored him in the pub. Others commented that their work enjoys a higher status than that of police and ambulance workers. Bruce referred to being frequently waved to by members of the public when in a fire engine. Moreover, the work conditions and hours and extended periods of non-work time meant they could have a significant life outside work.

As noted, all three informants were seeking to embed themselves further in their workplace, its culture and its affordances. The interviews revealed considerable levels of intersubjectivity in their conceptions of their work and work-related values. This may well be a product of the intensity, duration and shared nature of their working lives. Conversely, although engaged in shared work and a shared work environment underpinned by the SOE, there were distinct dissonances and differences in perspectives arising from the IT workers. Their personal and professional trajectories were also quite distinct. Two of the three articulated concerns about, and exercised distance from, the allegedly shared values and interactions of the workplace. So, unlike the firefighters, whose trajectories were more centripetal, these workers' trajectories were towards more peripheral participation, in so far as the team functioning was concerned. Then, the gymnasium, albeit without the range of institutional affordances of the fire station or the university, also presented an environment where there were shared interests and concerns. Here, there were both consonances and a coalescing of work-related practices and values associated with individual trajectories. All three participants' goals were intertwined with those of the workplace. In particular, the personal trainer characterises what is referred to as a contingent worker - not formally tenured within the workplace. Yet he and the other part-time worker enjoyed engagement in and reciprocity with the workplace. Similarly, for the part owners of the restaurant, work afforded them important opportunities associated with their personal and professional trajectories. However, for the waitress, there were only personal goals (i.e. to fund university attendance) to be secured.

Sitting within this analysis is evidence of interdependence between what is afforded the individual and individual engagement with it. For instance, even in the fire service there were quite distinct constructions of the purposes and practices of the command and control ethos that underpins emergency service provisions. These were seen as being helpful when they ordered the activities of fire officers in emergency incidents. Nevertheless, the officers themselves identified distinct construal in their responses to these requirements. For instance, Bruce, station manager and by rank the automatically appointed incident controller in an emergency response, lauded the command and control ethos for its operational efficacy, yet he derided its operation upon him from administrators senior to his position. Similarly, Ian, a ladder specialist, referred to having considerable autonomy in emergency situations because of his specialist expertise. Thus, although he might be given a general direction by the incident controller, he claimed to practise considerable autonomy in the conduct of his work during an emergency incident. More than that, he referred to enjoying the capacity to direct his own work and not be constrained by the decisions of others. Hugh referred to the long process it had taken for him to be employed as a fire officer, despite the fact that he was already a trained officer from the United Kingdom. There is also an apparent contradiction in the values of these individuals and the institutional practices of their workplace that must underpin participation in other forms of service, such as the 
military. Each of these fire officers referred to wanting to be a leader, and wanting to enjoy more freedom. Individually, each of their personal histories has included being self-employed or running a small business in which they had considerable autonomy. Yet, they were engaged in, and seemingly embedded in, work practices that sought to relegate individual autonomy to a series of practices that had to be appropriated and enacted uncritically. Perhaps it is within the situational discretion provided for these individuals to exercise their self and their autonomy when engaging in dangerous and confronting work where this autonomy and desire for leadership can be expressed. Similarly, another preference contrast is at play in the IT help desk area. At least some of these workers' preferences to work alone are being contravened by requirements, both physical and organisational, to work in teams. However, unlike the fire officers, they are not compensated by conducting high status work. Instead, they are subject to an electronic monitoring device that may be a poor substitute for public acclaim. This is more than speculation, as they report enjoying specific feedback from people who value their work.

Within the IT work there were clear differences in how affordances were interpreted and engaged. What for one worker was an openly social working environment, which welcomed and embraced workers and extended to out-of-work social activities, was seen quite differently by the two others. One expressed a preference for keeping work and social life separate, and therefore would not engage in social exchanges other than those required to conduct his work. Another IT worker elected to participate more peripherally. This may have been because of a previous workplace incident. However, what was clear in these different kinds of participation was that they were underpinned by distinct goals and intentions that were found in previous or pre-mediate experiences. The earlier experience of one worker was to separate work and personal life, another was to avoid unnecessary social interaction, whereas the third saw working collegiately and in ways which extended beyond the workplace as a desirable form of work practice. In a distinctly different way, it was how the workplace offered particular affordances to the workers in the gym that was central to their engagement and participation. It offered them quite different invitations to engage and work. Yet because of the consonance between these affordances and their personal trajectories, they were seen to be welcoming and highly invitational. So in these ways, there is a clear interdependence between the institutional facts (Searle, 1995) of the workplace and the bases of engagement by individuals, premised on their agentic action (Billett and Somerville, 2004). The bases for the interdependence were found in the degree of social press or agency of the social world and, relationally, individuals' engagement with that. While the institutional press and practices of the fire service were potent, it was important for, and generally valued by, the fire officers. The press of the IT and restaurant workplaces was also strong in different ways (i.e. shared environments), but the bases for engagement were more diverse, as was their enactment. Then again, a different kind of press was enacted in the gym, which was less premised on strong institutional practices than alignments between individuals' interests and trajectories. Again, this emphasises the relational nature of interactions between social and individual agency. 


\subsection{Individual learning and the remaking of work practice}

As individuals participate in their workplaces, they are also engaging in learning work. This learning work has two dimensions: (i) individual learning and (ii) the remaking of cultural practices that comprise their work. Much of the firemen's work is explicitly about learning: learning to improve their practice, learning to be more knowledgeable about the likely sources and prevention methods of fire. They are engaged in a cycle of technical preparation and maintaining readiness to act, which is all about learning the practice of responding to emergency incidents. Moreover, the workplace provides an environment in which this learning is supported and engaged with by the firefighters through their individual and shared activities. It is through their collective experiences and actions that they conduct their work in ways that are likely to be quite distinct from earlier and other firefighters. For instance, the decline in the number of fires to be extinguished arises from more safely constructed buildings, fire prevention strategies, and fire and smoke alarms. Consequently, the actual firefighting aspect of their work has declined, yet new applications for their skills have emerged in responding to motor vehicle accidents. Much of their new training is directed towards such scenarios. Also, Hugh claims, the work of the firefighters in this station in Australia is quite different from his earlier experiences in Wales. Similarly, the IT workers in the university are engaged in learning processes. Because their work has a highly dynamic quality in addressing emerging problems, establishing systems, refining those systems and engaging in the implementation of new systems, much of their work is inherently about learning and maintaining their competence in their work. Analogous to the firefighters' circumstances, the improved and more reliable performance of computers means that hardware failures are becoming less and less frequent. At the same time, software applications, their maintenance and updating are becoming more and more frequent. Given the decline in hardware failures, increasingly remote desktop help work is able to address the majority of computer-based problems. So these changes mean that, like the firefighters, these IT workers are actively engaged in the process of remaking the practice of what constitutes an information technology technician.

However, there are some distinct differences between the learning work of the firefighters and that of the information technology workers. The firefighters work for an organisation whose purposes are inherently about emergency services, and their promotion and well-being is vested in their perfect performance of their work. There is also an essential quality about working with others in moments of extreme emergency and a requirement for effective performance that in some ways transgresses the requirements of individual preferences for the conduct of work. Thus, being and working together is important. Yet the IT workers are not so pressed towards potent and collective goals. Much of their learning appears to be underpinned by their being as much disengaged from the shared practice as engaged with the shared practice. Although the workplace is reliant upon information technology, their work is mainly seen as servicing the more prestigious work of the university (i.e. research, teaching). Hence the levels of engagement across the two workplaces that have strong team qualities are quite distinct. Moreover, perhaps most sharply marked in the IT workplace are differences in affordances and engagement. Still, there are significant differences within the firefighting workplace. Ian is committed to working from home, while Hugh is required to undertake training and recognition of prior learning processes to have his firefighting skills 
recognised. But the learning and working of the firefighters is directed towards centripetal participation. This is less true of the IT workers, whose modes of participation and engagement are directed variously towards being peripheral, to find a new practice to participate in as well as centripetal participation.

The learning work of the other two workplaces is also shaped by interaction between individuals' personal goals and workplace affordances. For John, the learning work in the restaurant is all about developing further his business as both a restaurateur and an outsider caterer. In the exercise of his work he is learning to improve and extend his preferred vocation. This emphasis on management is even taking him to consider shifting from hospitality work, which has been the key source of his employment and sense of identity to date, to management work per se. Moreover, Robert is engaged in learning work such as developing capacities associated with dealing with members of the public and others, which comprises a personal short-term goal in terms of his improved workplace efficacy, but also a more long-term goal about fully owning his own restaurant. However, the learning work of the waitress is more about fulfilling the demands of her employer to the degree that she can maintain employment, thereby sustaining her other activities. The learning work of those in the gym is also varied. In different ways they are afforded particular opportunities, including those explicitly about learning. The manager is able to extend her skills and prospects through interacting with managers in other gymnasiums and the owner of the business. The personal trainer is also able to extend his knowledge through building up a diverse clientele and through engaging in an educational programme about health and fitness coaching. The parttime receptionist also learns through her work how to maintain that employment. However, unlike Rosie the waitress, she is able to apply her growing knowledge of physiotherapy through her paid part-time work. In these ways, learning and work are explicitly linked. However, the bases for, process of and outcomes of these experiences are different and in some ways quite distinct. These differences are not simply a product of immediate social factors; they are a product also of the individuals' interests and agency. So here, epistemological agency (Smith 2004) was evident in the enactment of individual learning and what could be identified as the remaking of cultural practices.

\subsection{Conclusion}

In summary and conclusion, this initial analysis of these four groups of workers' work and work practices indicates that there are distinct bases through which the workplace provides affordances and, in turn, how those affordances are engaged with, construed and constructed by the individuals. The dualisms here are not simple. They are richly interconnected and intertwined. The societal value and standing granted to firefighters is something generated outside their workplace but manifested in the practice and public execution of their work. The apparently contradictory mix of adherence to command and control protocols and the freedom afforded to have second forms of employment are more nuanced and relational bases for these workers to be highly integrated and strongly identify with being a firefighter and part of firefighting culture. In some ways, the work demands it. Yet, clearly, some contravene that by being seen not to be competent or committed to their work. The personal histories of the IT workers are exercised in different ways 
within work that is hidden from many of those who benefit from it. Instead of public adulation and support, some of these workers rely on electronic feedback from client surveys as a means to demonstrate their worth. Equally, the workers in the gymnasium and the restaurant are seeking quite different bases for the continuity and confirmation of their being effective through that work. For some, this comes from within the workplace, but for others from outside it. In all, this early work and tentative findings demonstrate how work and learning work are integrated in different ways and for different purposes across these four workplaces. It emphasises the relational nature of the interdependencies between the social and individual contributions, yet articulates strongly how the confluence of social and individual is exercised perhaps most strongly by individuals through their construal and construction (learning, if you like) and that the social practice is as much dependent on these individuals as the individuals upon it. Hence, even from the perspective of the remaking of cultural practices, such as those skills required for workplaces, the individual appears to stand as an important component and one that needs to be considered by pragmatic agenda associated with learning and learning throughout working life.

\section{References}

Archer, M.S. (2000). Being Human: the problem of agency. Cambridge: Cambridge University Press.

Bauer, J., Festner, D., Gruber, H., Harteis, C., \& Heid, H. (2004). The effects of epistemological beliefs on workplace learning. Journal of Workplace Learning, 16(5), 284-292.

Bhaskar, R. (1998). The possibility of naturalism. London: Routledge.

Bierema, L.L. (2001). Women, Work, and Learning. In: T. Fenwick (Ed.), Sociocultural perspectives on learning through work (pp. 53-62). San Francisco: Jossey Bass/Wiley.

Billett, S. (2004). Co-participation at work: Learning through work and throughout working lives. Studies in the Education of Adults, 36(2), 190-205.

Billett, S. (2005b). Relational interdependence between social and individual agency in work and working life. Mind, Culture and Activity, 12(4).

Billett, S., \& Somerville, M. (2004). Transformations at work: Identity and learning. Studies in Continuing Education, 26(2), 309-326.

Cole, M. (1998). Can cultural psychology help us think about diversity? Mind, Culture and Activity, 5(4), 291-304.

Eraut, M. (2004). Informal learning in the workplace. In: H. Rainbird, A. Fuller \& A. Munro (Eds.), Workplace Learning in context. London: Routledge

Fenwick, T. (1998). Women's Development of Self in the Workplace. International Journal of Lifelong Learning, 17(3), 199-217.

Fenwick, T. (2002). Lady, Inc.: women learning, negotiating subjectivity in entrepenurial discourses. International Journal of Lifelong Education, 21(2), 162-177.

Fuller, A., \& Unwin, A. (2003). Fostering workplace learning:Looking through the lens of aprenticeships. European Educational Research Journal, 2(1), 41-55.

Fuller, A., \& Unwin, L. (2002). Developing pedagogies for the workplace. In: K. Evans, P. Hodkinson \& L. Unwin (Eds.), Working to learn: Transforming workplace learning. London: Kogan-Page.

Giddens, A. (1991). Modernity and self-identity: Self and Society in the Late Modern Age. Stanford: Stanford University Press. 
Leontyev, A.N. (1981). Problems of the development of the mind. Moscow: Progress Publishers.

Malle, B.F., Moses, L.J., \& Baldwin, D.A. (2001). Introduction: The Significance of Intentionality. In: B.F. Malle, L.J. Moses \& D.A. Baldwin (Eds.), Intentions and Intentionality: Foundations of Social Cognition (pp. 1-26). Cambridge, Massachusetts: The MIT Press.

Noon, M., \& Blyton, P. (1997). The realities of work. Basingstoke, Hants: Macmillan.

Pusey, M. (2003). The Experience of Middle Australia. Cambridge, UK: Cambridge University Press.

Rogoff, B. (1990). Apprenticeship in thinking - cognitive development in social context. New York: Oxford University Press.

Rogoff, B. (1995). Observing sociocultural activity on three planes: Participatory appropriation, guided participation, apprenticeship. In: J. W. Wertsch, A. Alvarez \& P. del Rio (Eds.), Sociocultural studies of mind (pp. 139-164). Cambridge, UK: Cambridge University Press.

Rogoff, B., \& Gauvain, M. (1984). The cognitive consequences of specific experiences weaving versus schooling among the Navajo. Journal of Cross-Cultural Psychology, 15(4), 453-475.

Rose, N. (1990). Governing the soul: The Shaping of the Private Self. London: Routledge.

Scribner, S. (1984). Studying working intelligence. In: B. Rogoff \& J. Lave (Eds.), Everyday cognition: Its development in social context (pp. 9-40). Cambridge, Mass: Harvard University Press.

Scribner, S. (1985a). Knowledge at work. Anthropology and Education Quarterly, 16, 199206.

Scribner, S. (1985b). Vygostky's use of history. In: J.V. Wertsch (Ed.), Culture, communication and cognition: Vygotskian perspectives (pp. 119-145). Cambridge, UK: Cambridge University Press.

Scribner, S. (1997/1990). A sociocultural approach to the study of mind. In: E. Tobah, R.J. Falmagne, M.B. Parlee, L.M. Martin \& E.A.S. Kapelman (Eds.), Mind and Social Practice: Selected Writings of Sylvia Scribner. (pp. 266-280.). Cambridge, UK: Cambridge University Press.

Searle, J.R. (1995). The Construction of Social Reality. London: Penguin.

Smith, R.J. (2004). Necessity in action: The epistemological agency of the new employee. Unpublished Master of Education, Griffith University, Brisbane.

Solomon, N. (1999). Culture and difference in workplace learning. In: D. Boud \& D.J. Garrick (Eds.), Understanding Learning at Work (pp. 119-131). London: Routledge.

Somerville, M. (2002). Changing Masculine Work Cultures. Paper presented at the Envisioning practice -- Implementing change, Gold Coast.

Valsiner, J. (1994). Bi-directional cultural transmission and constructive sociogenesis. In: W. d. Graaf \& R. Maier (Eds.), Sociogenesis Re-examined (pp. 101-134). New York: Springer.

Valsiner, J., \& Van der Veer, R. (2000). The Social Mind: The construction of an idea. Cambridge, UK: Cambridge University Press.

Wertsch, J.V. (1998). Mind as Action. New York: Oxford University Press. 